\title{
Pulmonary metastasectomy: limits to credibility
}

\author{
Tom Treasure ${ }^{1}$, Fergus Macbeth ${ }^{2}$ \\ ${ }^{1}$ Clinical Operational Research Unit, University College London, London, UK; ${ }^{2}$ Centre for Trials Research, Cardiff University, Cardiff, UK \\ Contributions: (I) Conception and design: Both authors; (II) Administrative support: None; (III) Provision of study materials or patients: None; (IV) \\ Collection and assembly of data: Both authors; (V) Data analysis and interpretation: Both authors; (VI) Manuscript writing: Both authors; (VII) Final \\ approval of manuscript: Both authors. \\ Correspondence to: Tom Treasure. Clinical Operational Research Unit, University College London, London, UK. Email: tom.treasure@gmail.com.
}

\begin{abstract}
Lung metastases are a common site of spread for many malignant tumours. Pulmonary metastasectomy has been practiced for many years for sarcomas and is now becoming increasingly frequently advocated for patients with many other tumours, especially colorectal cancer. In this article we argue that this procedure is one framed by therapeutic opportunity and not supported by strong evidence. It is potentially harmful and may not be effective. Our argument is based on several important issues: (I) the vagueness of the concept of "oligometastases" and its biological implausibility; (II) the flaws in the often-cited observational evidence, especially selection bias; (III) the lack of any reliable randomised trial evidence of improved survival but evidence of harm; (IV) the failure of strategies to detect metastases earlier to influence overall survival. The introduction of stereotactic radiotherapy and image-guided thermal ablation have made the urge to treat lung metastases stronger but without any good evidence to justify their use. We acknowledge the problems of carrying out randomised trials when there is a clear lack of equipoise in the clinical teams involved but believe that there is an ethical need to do so. Many patients are probably being given false hope of cure or prolonged survival but are at risk of harm from pulmonary metastasectomy or ablation. It is possible that a few patients may benefit but without better evidence we do not know which, if any, do.
\end{abstract}

Keywords: Pulmonary metastasectomy; thoracic surgery; cancer; oligometastatic disease

Submitted Oct 21, 2019. Accepted for publication Mar 23, 2020.

doi: $10.21037 /$ jtd.2020.03.106

View this article at: http://dx.doi.org/10.21037/jtd.2020.03.106

"You believe that easily which you wish for earnestly." Terence, from his play Phormio 161 BC.

\section{Introduction}

Without any apology, we admit that the aim of this article is to question the role of pulmonary metastasectomy-a procedure which we believe is without logical foundation or reliable supporting evidence. We have no relevant financial or academic conflicts of interest as we are both long retired from clinical practice. But we are driven by a desire to see rationality brought to the topic and to ensure patients are spared pointless and perhaps harmful intervention. Our introductory material is based on a presentation at the
2019 World Lung Cancer conference in a "Controversy Session" (1). Speakers were invited to be provocative and we approach this article in the same spirit.

The Controversy Session was given the catchy title "Hunting a ghost for 25 years - Will We Ever Catch OMD?". The abbreviation "OMD" indicates that "oligometastatic disease" is seen as an established diagnosis but all four speakers pointed to the lack of an agreed number or indeed whether OMD could be defined by a specific number (1-4). A clinical state characterised by "fewness" of metastases should alert everyone to the vagueness and uncertainty of such a diagnostic label: any threshold number for inclusion is likely to be arbitrary. Here we present a sceptical view of the diagnosis of OMD 
and its treatment, based on a logical sequence of hypothesis, evidence and rebuttal (5). Rather than a ghost which we might catch, as suggested by the title of the International Association for the Study of Lung Cancer (IASLC) Controversy Session, we are inclined to regard this as an oligometastatic myth.

\section{A bit of biology}

Lung is one of the commonest sites for metastasis. The cancer reaches the lung parenchyma in the mixed venous blood. Other than in situations where there is a right to left shunt, the lungs provide a filtering mechanism. The seed and soil concept promoted by the London surgeon, Stephen Paget (6) explains the predilection of some cancers for certain sites, but the basic mechanism of filtration by the lungs remains an important factor (7). Because modern computerised tomography (CT) scans have excellent resolution, lung metastases more than a few millimetres in diameter can now be detected in reasonably healthy lungs. The metastases also will also show up on fluorodeoxyglucose positron emission tomography (FDG/PET) scans.

It is a matter of common observation that a patient whose primary tumour has been removed and is apparently disease-free can subsequently develop metastases. These previously undetected micrometastases were always there but were below the limits of imaging sensitivity. So, it is sadly true that in patients with one or a few metastases, more almost always become evident over time. Why then is it logical to believe that patients with a few detected metastases might be rendered disease-free by removing them? It would be like standing under a tree in the autumn and seeing one fallen leaf and believing this to be a unique event. In nearly all cases, if you look up, you will see others on their way down. This is why it was accepted 25 years ago that the presence of even one metastasis should be seen as evidence of disseminated disease. It meant that metastatic disease required systemic rather local treatment if survival were to be influenced.

We can pinpoint the explicit acceptance of this understanding for both breast and lung cancer.

There had been a growing case during the 1970s for breast surgery to be conserved for management of the primary cancer (8-10). If the cancer had the propensity to metastasise it should be regarded as systemic from the outset and managed with adjuvant systemic treatments. Halsted's radical mastectomy was then gradually abandoned, sparing millions of women mutilating but unavailing attempts at surgical "cure" $(11,12)$. This change of approach was generally welcomed. However there is a report from 2006 of a surgeon removing as many as 124 lung metastases from breast cancer at one operation (13). He appeared confident that there was not a $125^{\text {th }}$-an instance of believing what you "wish for earnestly".

For lung cancer, better detection of lymphatic and blood borne metastases, spared many patients an unavailing thoracotomy. Fewer were operated on but 5 -year survival rates for those who were improved from about $25 \%$ (14) to better than $50 \%$ (15) because of better detection of metastases at diagnosis. Promotion of extensive mediastinal lymphadenectomy has led to a return to operating on patients whose cancers have spread beyond primary resection, despite a lack of secure evidence (16). This is probably a backward step when there has been an evidence-based move away from radical clearance of lymph nodes in the surgery of breast, colorectal and ovarian cancers $(8,10,17-20)$.

\section{Oligometastasis_a made up term}

The promotion of treatment of blood borne metastases under the banner of OMD now threatens to put the clock back to a more reckless approach to cancer surgery. In 1995 Hellman and Weichselbaum wrote "Systemic metastases are multiple and widespread, and when subclinical are referred to as micrometastases. Under these circumstances, treatment of local or regional disease should not affect survival." (21). They then went on to hypothesise, without offering any evidence, that this might not always be the case. They proposed the term "oligometastases" to describe a clinical state between freedom from metastases and their "extensive and widespread" presence. They offered no plausible biological mechanism and none has been offered since. If the frequency distribution of the number of metastases showed a bimodal distribution with a second mode in the $1-5$ or $1-3$ range then there would be a mathematical reason to suspect there are two disease types, polymetastatic and oligometastatic. But there is no evidence that there is such a distribution. It is more likely that there is a skewed distribution with long tail tapering off to the uncommon state of a truly solitary metastasis. 
Box 1 Framing disease by its response to treatment

Diagnostic frames shift over time. In the $18^{\text {th }}$ century the term "dropsy" described a condition which we would recognise as severe generalised water retention, or oedema. William Withering observed that some people with dropsy were helped by infusions of foxglove. Richard Bright discovered that some had protein in their urine and at autopsy he found shrivelled kidneys. So, the clinical diagnosis of dropsy was split and reframed by morbid anatomy according to whether it was the heart or the kidneys that failed

Clinical science over the next 200 years framed the many types of kidney disease but then treatment became possible with dialysis and transplantation. Long-term survival was possible but cripplingly expensive for most individuals and their families. In 1972 US Congress passed Public Law 92-603 and with it framed a new diagnosis: end-stage renal disease (ESRD). Patients with ESRD were entitled to federal funding. In 1974 ESRD appeared for the first time in PubMed in a paper about public financing. ESRD has been used in titles or abstracts 15,282 times since and runs at over a thousand citations a year

Another familiar example was the emergence of non-small cell lung cancer (NSCLC) as a diagnostic frame. In the 1970s, adenocarcinoma, squamous cell and large cell anaplastic cancer were framed by microscopy. Operation offered 25-30\% 5-year survival, but for oat cell (or small cell) cancers, surgery nearly always failed due to widespread metastases. The new chemotherapy drugs made small-cell carcinoma melt away, if only temporarily. It may seem strange to frame a disease by what it is not, but that is exactly how NSCLC is framed. Lung cancer was dichotomised based on response to treatments. Interestingly NSCLC is now being unbundled by tumour markers, genomes and targeted treatments and reframed as a result

\section{Framing disease by therapeutic opportunity (Box 1)}

OMD is no more and no less than what is on the label-it describes cancer with few metastases. If there is no cogent biological mechanism, and there is an arbitrary cut-off in a continuous distribution, we are left to conclude that OMD is "framed" by the therapeutic opportunity it offers $(1,22)$. Metastases fewer than can be counted on the fingers of one hand are amenable to local eradication with surgery, stereotactic ablative radiotherapy (SABR) or image-guided thermal ablation (IGTA). With more than five metastases it becomes increasingly impractical to attempt local control. The surgeon of the 124 lung metastases, resected an average of 10 in a total of more than 300 patients (13) but placing some limit on the number you can treat makes sense to most doctors. For SABR it has been said that there must be "few enough to zap". So, it seems that this is the art of the possible rather than a precise science. The final speaker in the Controversy Session remarked that OMD was something "just made up" adding with characteristic Australian bluntness "by a couple of blokes in a pub!". Five or fewer identified metastases fits a working definition of OMD (23). It is the therapeutic opportunity that makes OMD a useful working diagnosis and in an international survey $99 \%$ of 1,007 radiation oncologists regarded OMD as something for them to treat (24).

\section{Observational evidence of outcome...: case reports, surgical series and a registry}

From 1987 (about the time when metastasectomy came into regular usage) to the end of 2018 there have been 2,166 papers with metastasectomy in the title or abstract. The rise has been exponential. Pulmonary metastasectomy for sarcoma became an established practice from the 1970s, rather than being an occasional individualised decision, as it had been up to then. Pulmonary metastasectomy became a standard of care (25). One underlying reason is that of patients with sarcoma who have metastatic disease, the lungs are affected in $80 \%$ and are the only site in $60 \%$ (26). Another is that these are often young patients, but why the young should suffer needlessly deserves some thought. There is still a need for proof of clinical effectiveness. Memorial Sloan-Kettering authors have revisited their original series after two decades $(27,28)$ and they have found, along with others, that long survival with this disease is possible but in the absence of direct controls or even cogent comparison data (29) they have not proven that survival is a result of lung resection (30). Claims have been made that with repeat metastasectomy results are even better, neglecting the inescapable conclusion that this is because there is a dwindling denominator of people living long term with metastatic disease whose lives are punctuated by episodes of treatment to which their longevity is erroneously attributed (31).

The Memorial Sloan-Kettering surgeons reported their series of operations for the more common primary source, colorectal cancer, in the 1970s and published 10-year results in 1992 (32). In patients with metastatic colorectal cancer, it has consistently been found that the most powerful determinants of the length of survival is a solitary metastasis and 
a long interval since primary resection (average 2 3 years) (33). But there was a growing mood that, provided the metastases were technically amenable to resection, their number was no obstacle and that neither early nor synchronous appearance of lung metastases was a barrier to operation. However, these patients with less constrained indications for metastasectomy were not doing well. The joint publication with Duke University in 2009, including 378 patients, concluded with a firm statement that "Medical management alone should be considered standard for patients who have both three or more pulmonary metastases and less than 1 year DFI." (34). That advice has not been heeded.

\section{A fair test of clinical effectiveness: randomised controlled trials (RCTs)}

The central problem is that there have been no attempts to quantify what would be the probability of survival for similar patients not having a metastasectomy. In 1980 Aberg challenged the practice pointing out that the survival times claimed as attributable to surgery might have been the result of selecting patients more likely to survive naturally (35). His paper has been overlooked and ignored, while authors more often cite those who agree with them (36). The publication of the International Registry of Lung Metastasis (37) reported on 5206 patients. It is regarded as the landmark publication, but it contains data only from patients who had metastasectomy with no attempt to offer a comparator.

The OMD hypothesis can only be reliably tested in RCTs. We are aware of only three RCTs of treatment of carcinoma metastases, comparing active local treatment with "no treatment":

(I) CLOCC is a trial of radiofrequency ablation of liver metastases from colorectal cancer (38);

(II) SABR-COMET is a trial of stereotactic radiotherapy ablation of metastases from any primary carcinoma to any secondary site with the exception of specified patterns of brain metastases (39);

(III) PulMiCC is a trial of surgical metastasectomy of lung metastases from colorectal cancer (40).

All three RCTs are small with 119, 99 and 65 participants randomised respectively.

Because the number of metastases is the most powerful prognostic factor it is very important that the frequency of metastases is well balanced in the two arms of the RCT.

The CLOCC trial reported no significant survival difference at 5 years (41) but a survival difference at 5-10 years, favouring ablation, with only 11 patients still alive. But the ablation arm included more patients with solitary metastases ( $25 \%$ versus $12 \%$ ), and fewer with $5+$ (37\% versus $56 \%$ ) than the control arm. This important imbalance is likely to have influenced the outcome (38).

SABR-COMET randomised patients with five or fewer metastases and appeared to show a benefit favouring intervention (hazard ratio 0.57, 95\% CI: 0.30-1.10; $\mathrm{P}=0.090$ ). But again, there was an important imbalance in the distribution of metastasis frequency. The stratification was set at between 1-3 and 4-5 metastases and, by chance, there was a $10 \%$ excess of solitary metastases in the intervention group (46\% versus 36\%).

There was also an important imbalance in the primary site. The 99 patients included those with more than five different primary sites and more than five different secondary sites and so it is not surprising that the two arms included patients with very different characteristics, some well-known to have prognostic significance. For example, the intervention arm had a predominance of patients with breast and prostate cancer likely to have a better prognosis. So, the seemingly impressive survival benefit in this small randomised Phase 2 trial is less meaningful in light of this prognostic factor imbalance and the upper limit of the $95 \%$ CI being 1.10. The SABR intervention arm also showed a $20 \%$ increase in Grade 2 or worse adverse events and a $4.5 \%$ rate of treatment-related deaths.

In the PulMiCC trial balance was ensured by including minimisation in the randomisation process (42). It demonstrated no significant difference in survival. The hazard ratio for death within 5 years, was 0.82 (95\% CI: $0.43-1.56)(40)$.

Observational follow-up studies of lung metastasectomy (33) generally report 5 -year survival of around $40 \%$. Because it is assumed that the 5 -year survival of a comparable untreated population would be near zero, this survival is always attributed to the effect of the operation. Of relevance in the three RCTs is the survival in the control arms. In both CLOCC and PulMiCC the 5-year survival of the untreated controls was around 30\% and in SABR-COMET the 3-year survival was around $25 \%$. In light of these findings, the belief that the absolute increase in survival approaches $40 \%$ at 5 years is no longer justified.

As far as we are aware there have only been these three RCTs addressing in various ways the value of removing or ablating oligometastases, all very small. Two (SABRCOMET and CLOCC) are potentially flawed by imbalances in key prognostic factors. PulMiCC shows no difference in survival. We acknowledge that the point 
estimate of the hazard ratio in all three appears to favour intervention but believe that the question remains open. Despite all those with vested interests who might argue otherwise, larger definitive trials are ethically justified and still needed to determine whether this policy does in fact improve survival and, if so, in which patients. It remains very probable that many patients are being harmed without any real benefit.

\section{Why were so few patients randomised?}

It is likely that thousands of patients around the world are undergoing metastasectomy every year but only 283 have ever been entered into RCTs. This could never happen with a new pharmaceutical intervention. In CLOCC there were 119 patients (control 59; intervention 60); in SABRCOMET 99 patients (control 33; intervention 66) and in PulMiCC 65 patients (control 33; intervention 32). Neither CLOCC nor SABR-COMET described the process of screening for recruitment and the size of the population from which the few randomised patients were drawn. In PulMiCC we have information (with informed consent) from all 512 patients considered in Stage 1 of the trial recruitment process. The three most actively recruiting centres were asked to provide reasons why patients in Stage 1 were not subsequently randomised. We wanted to establish who made the decision not to randomise and what clinical management then followed. If participants were deemed ineligible, we asked for the reason. Of 155 patient participants in Stage 1 of the trial, 41 decided not to be randomised and to make their own decision. Of these, 22 opted to have metastasectomy and 19 not to. When the clinicians made the decision 77/78 (99\%) patients had metastasectomy. Ten patients had other pathology, nine lung cancer and one carcinoid. The protocol placed no constraint on the number of metastases but one unit set its own limits at 2-4 excluding patients with only one metastasis from the trial.

All this suggests that the clinicians did not really have equipoise about the value of metastasectomy whereas the patients did. With such widespread prior belief, it is no surprise that participation in RCTs is so rare.

\section{Trials of earlier detection of metastases for treatment}

The first RCT testing the merits of post-primary resection monitoring with carcinoembryonic antigen screening was the CEA Second Look (CEASL) trial which recruited from 1982 to $1993(43,44)$. The interest was in treating early local recurrence but included the then growing practice of liver metastasectomy (45) and some lung metastasectomy operations. There was no survival advantage but instead a detrimental effect, but not to the level of statistical significance.

There have now been 16 RCTs including 3,325 patients and two meta-analyses investigating whether or not increased surveillance of radically treated patients with colorectal cancer improves survival $(46,47)$. More intensive monitoring with increasingly sensitive tests appears to detect metastases about 1-2 years sooner. This results in more patients getting liver and lung metastasectomies, but there is no demonstrable survival benefit.

\section{Some conclusions from the limited evidence}

Observational studies without reliable controls, very small RCTs with important imbalance in key prognostic factors, and the meta-analyses of monitoring trials leave us without strong evidence that the surgical removal or ablation of metastases improves survival. But why do so many clinicians believe that it does and persuade their patients to be treated? There are two reasons.

First, confirmation bias is a powerful force and the "evidence" from observational studies appears convincing to a believer. But although these suggest an association between treatment of metastases and longer survival time, we know that there is longer natural survival with fewer metastases. The association may not therefore be causation and it might be that a longer time alive provides opportunities to give more treatments. You can only treat the survivors. OMD is metastatic disease distinguished by an arbitrarily defined fewness of metastases. By selecting for treatment on the basis of fewness you are choosing the least aggressive cancer cases. If we attribute survival to treatment when it is in fact due to selection, we can delude ourselves. We may be engaging in "wishful thinking" (48).

Secondly, there is a lot of money already invested (24). There is also a lot of money to be made by industry, for-profit medical providers and by interventional practitioners. That is the reality. Surgical resection of lung metastases was already commonplace by the end of the twentieth century, certainly for sarcoma and increasingly for colorectal cancer (49). What probably has led to increasing in interest in OMD as a treatable state has been the development of SABR and IGTA. This has meant that radiation oncologists and interventional 
radiologists eager to use their new technologies could get in on the action. The inappropriately enthusiastic and uncritical commentary that accompanied the publication of SABRCOMET reflects that (50).

The vision of managing cancer in a similar way to other chronic diseases is seen as justification for metastasectomy. Cancer may run a chronic course during which the patient leads a good life, punctuated by treatment. But the survival advantage attributed to treatment may be greatly overestimated and the potential harms underplayed or under-reported. While there may be a correlation between the number of treatments and the length of survival, ongoing survival provides opportunity for more treatments to be given. We understand the need for clinicians to offer their patients apparently life-prolonging interventions, but we hope that they can look at the actual evidence more critically and seek trustworthy comparative data. Without those, their recommendations may be mere wishful thinking and their patients will be given false hope and hollow promises.

\section{Acknowledgments}

Funding: None.

\section{Footnote}

Provenance and Peer Review: This article was commissioned by the Guest Editor (Khosro Hekmat) for the series "Pulmonary Metastases" published in Fournal of Thoracic Disease. The article has undergone external peer review.

Conflicts of Interest: Both authors have completed the ICMJE uniform disclosure form (available at http://dx.doi. org/10.21037/jtd.2020.03.106). The series "Pulmonary Metastases" was commissioned by the editorial office without any funding or sponsorship. The authors have no other conflicts of interest to declare.

Ethical Statement: The authors are accountable for all aspects of the work in ensuring that questions related to the accuracy or integrity of any part of the work are appropriately investigated and resolved.

Open Access Statement: This is an Open Access article distributed in accordance with the Creative Commons Attribution-NonCommercial-NoDerivs 4.0 International License (CC BY-NC-ND 4.0), which permits the non- commercial replication and distribution of the article with the strict proviso that no changes or edits are made and the original work is properly cited (including links to both the formal publication through the relevant DOI and the license). See: https://creativecommons.org/licenses/by-nc-nd/4.0/.

\section{References}

1. Treasure T. CS01.01 "Hunting a Ghost for 25 Years - Will We Ever Catch OMD?" - No. J Thorac Oncol 2019;14:S77.

2. Belderbos J. CS01.02 "Hunting a Ghost for 25 Years - Will We Ever Catch OMD?" - Yes. J Thorac Oncol 2019;14:S77-8.

3. Scorsetti M. CS01.03 Technical Reasons of Local Treatment Define the Limits of NSCLC OMD in Terms of Number of Metastases, Not a Fixed Number. J Thorac Oncol 2019;14:S78-9.

4. Wright G. CS01.04 NSCLC OMD is Defined by a Fixed Maximum Number of Metastases, Not Technical Reasons of Local Treatment. J Thorac Oncol 2019;14:S79.

5. Treasure T, Macbeth F. Is Surgery Warranted for Oligometastatic Disease? Thorac Surg Clin 2016;26:79-90.

6. Paget $\mathrm{S}$. The distribution of secondary growths in cancer of the breast. Lancet 1889;133:571-3.

7. Fidler IJ, Poste G. The "seed and soil" hypothesis revisited. Lancet Oncol 2008;9:808.

8. Fisher B. The surgical dilemma in the primary therapy of invasive breast cancer: a critical appraisal. Curr Probl Surg 1970:1-53.

9. Ellis H. If I had... If my wife had cancer of the breast. Br Med J 1978;1:896-7.

10. Veronesi U, Saccozzi R, Del Vecchio M, et al. Comparing radical mastectomy with quadrantectomy, axillary dissection, and radiotherapy in patients with small cancers of the breast. N Engl J Med 1981;305:6-11.

11. Berwick DM. The science of improvement. JAMA 2008;299:1182-4.

12. Mukherjee S. A Radical Idea in "The Emperor of All Maladies". The Emperor of the Maladies. New York: Scribner, 2010:60-72.

13. Rolle A, Pereszlenyi A, Koch R, et al. Is surgery for multiple lung metastases reasonable? A total of 328 consecutive patients with multiple-laser metastasectomies with a new 1318-nm Nd:YAG laser. J Thorac Cardiovasc Surg 2006;131:1236-42.

14. Belcher JR. Thirty years of surgery for carcinoma of the bronchus. Thorax 1983;38:428-32. 
15. Chemotherapy in non-small cell lung cancer: a metaanalysis using updated data on individual patients from 52 randomised clinical trials. Non-small Cell Lung Cancer Collaborative Group. BMJ 1995;311:899-909.

16. Mokhles S, Macbeth F, Treasure T, et al. Systematic lymphadenectomy versus sampling of ipsilateral mediastinal lymph-nodes during lobectomy for nonsmall-cell lung cancer: a systematic review of randomized trials and a meta-analysis. Eur J Cardiothorac Surg 2017;51:1149-56.

17. Fisher B, Redmond C, Fisher ER, et al. Ten-year results of a randomized clinical trial comparing radical mastectomy and total mastectomy with or without radiation. N Engl J Med 1985;312:674-81.

18. Fisher B, Bauer M, Margolese R, et al. Five-year results of a randomized clinical trial comparing total mastectomy and segmental mastectomy with or without radiation in the treatment of breast cancer. $\mathrm{N}$ Engl J Med 1985;312:665-73.

19. Georgiou PA, Mohammed AS, Brown G, et al. Extended lymphadenectomy for locally advanced and recurrent rectal cancer. Int J Colorectal Dis 2017;32:333-40.

20. Harter P, Sehouli J, Lorusso D, et al. A Randomized Trial of Lymphadenectomy in Patients with Advanced Ovarian Neoplasms. N Engl J Med 2019;380:822-32.

21. Hellman S, Weichselbaum RR. Oligometastases. J Clin Oncol 1995;13:8-10.

22. Treasure T. Oligometastatic cancer: an entity, a useful concept, or a therapeutic opportunity? J R Soc Med 2012;105:242-6.

23. Palma DA, Haasbeek CJ, Rodrigues GB, et al. Stereotactic ablative radiotherapy for comprehensive treatment of oligometastatic tumors (SABR-COMET): study protocol for a randomized phase II trial. BMC Cancer 2012;12:305.

24. Lewis SL, Porceddu S, Nakamura N, et al. Definitive Stereotactic Body Radiotherapy (SBRT) for Extracranial Oligometastases: An International Survey of $>1000$ Radiation Oncologists. Am J Clin Oncol 2017;40:418-22.

25. Martini N, Huvos AG, Mike V, et al. Multiple pulmonary resections in the treatment of osteogenic sarcoma. Ann Thorac Surg 1971;12:271-80.

26. Kager L, Zoubek A, Potschger U, et al. Primary metastatic osteosarcoma: presentation and outcome of patients treated on neoadjuvant Cooperative Osteosarcoma Study Group protocols. J Clin Oncol 2003;21:2011-8.

27. Beattie EJ, Harvey JC, Marcove R, et al. Results of multiple pulmonary resections for metastatic osteogenic sarcoma after two decades. J Surg Oncol 1991;46:154-5.
28. Beattie EJ, Jr. Surgical treatment of pulmonary metastases. Cancer 1984;54:2729-31.

29. Treasure T, Moller H, Fiorentino F, et al. Forty years on: pulmonary metastasectomy for sarcoma. Eur J Cardiothorac Surg 2013;43:799-800.

30. Treasure T, Fiorentino F, Scarci M, et al. Pulmonary metastasectomy for sarcoma: a systematic review of reported outcomes in the context of Thames Cancer Registry data. BMJ Open 2012. doi 10.1136 bmjopen-2012-00736.

31. Treasure T, Mineo T, Ambrogi V, et al. Survival is higher after repeat lung metastasectomy than after a first metastasectomy: Too good to be true? J Thorac Cardiovasc Surg 2015;149:1249-52.

32. McCormack PM, Burt ME, Bains MS, et al. Lung resection for colorectal metastases. 10-year results. Arch Surg 1992;127:1403-6.

33. Gonzalez M, Poncet A, Combescure C, et al. Risk factors for survival after lung metastasectomy in colorectal cancer patients: a systematic review and meta-analysis. Ann Surg Oncol 2013;20:572-9.

34. Onaitis MW, Petersen RP, Haney JC, et al. Prognostic factors for recurrence after pulmonary resection of colorectal cancer metastases. Ann Thorac Surg 2009;87:1684-8.

35. Aberg T, Malmberg KA, Nilsson B, et al. The effect of metastasectomy: fact or fiction? Ann Thorac Surg 1980;30:378-84.

36. Fiorentino F, Vasilakis C, Treasure T. Clinical reports of pulmonary metastasectomy for colorectal cancer: a citation network analysis. Br J Cancer 2011;104:1085-97.

37. Pastorino U, Buyse M, Friedel G, et al. Long-term results of lung metastasectomy: prognostic analyses based on 5206 cases. J Thorac Cardiovasc Surg 1997;113:37-49.

38. Ruers T, van Coevorden F, Punt CJ, et al. Local Treatment of Unresectable Colorectal Liver Metastases: Results of a Randomized Phase II Trial. J Natl Cancer Inst 2017;109:djx015.

39. Palma DA, Olson R, Harrow S, et al. Stereotactic ablative radiotherapy versus standard of care palliative treatment in patients with oligometastatic cancers (SABRCOMET): a randomised, phase 2, open-label trial. Lancet 2019;393:2051-8.

40. Treasure T, Farewell V, Macbeth F, et al. Pulmonary Metastasectomy in Colorectal Cancer (PulMiCC): a multicentre randomized clinical trial. Trials 2019. Available online: https://www.researchsquare.com/browse?author=tr easure \&offset $=0 \&$ status $=$ all 
41. Ruers T, Punt C, van Coevorden F, et al. Radiofrequency ablation combined with systemic treatment versus systemic treatment alone in patients with non-resectable colorectal liver metastases: a randomized EORTC Intergroup phase II study (EORTC 40004). Ann Oncol 2012;23:2619-26.

42. Altman DG, Bland JM. Treatment allocation by minimisation. BMJ 2005;330:843.

43. Treasure T, Monson K, Fiorentino F, et al. Operating to remove recurrent colorectal cancer: have we got it right? BMJ 2014;348:g2085.

44. Treasure T, Monson K, Fiorentino F, et al. The CEA Second-Look Trial: a randomised controlled trial of carcinoembryonic antigen prompted reoperation for recurrent colorectal cancer. BMJ Open 2014;4:e004385.

45. Grunhagen D, Jones RP, Treasure T, et al. The history of adoption of hepatic resection for metastatic colorectal

Cite this article as: Treasure T, Macbeth F. Pulmonary metastasectomy: limits to credibility. J Thorac Dis 2021;13(4):26032610. doi: $10.21037 /$ jtd.2020.03.106 cancer: 1984-95. Crit Rev Oncol Hematol 2013;86:222-31.

46. Mokhles S, Macbeth F, Farewell V, et al. Meta-analysis of colorectal cancer follow-up after potentially curative resection. Br J Surg 2016;103:1259-68.

47. Jeffery M, Hickey BE, Hider PN, et al. Follow-up strategies for patients treated for non-metastatic colorectal cancer. Cochrane Database Syst Rev 2016;11:CD002200.

48. Palma DA, Salama JK, Lo SS, et al. The oligometastatic state - separating truth from wishful thinking. Nat Rev Clin Oncol 2014;11:549-57.

49. Fiorentino F, Hunt I, Teoh K, et al. Pulmonary metastasectomy in colorectal cancer: a systematic review and quantitative synthesis. J R Soc Med 2010;103:60-6.

50. Loo BW Jr, Diehn M. SABR-COMET: harbinger of a new cancer treatment paradigm. Lancet 2019;393:2013-4. 